TRANSFER

Reception Studies

vol. 5 (2020): 115-142

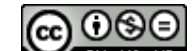

\title{
Zwischen Komik und Postironie. Die Spielarten des Humors in Tyll von Daniel Kehlmann
}

\section{Between comedy and postirony. The variations of humor in Tyll by Daniel Kehlmann}

\begin{abstract}
In his novel Tyll, Daniel Kehlmann explores the limits of humor by, among other things, mixing comedy with seriousness or using postirony. This article examines the varieties of humor and methods of creating comic elements, which Kehlmann uses differently in his novel, both on the linguistic level and in the construction and content of the novel. In addition, Tyll provides some examples of postirony, as an irony of irony, which describes a literary process of transcending irony for example by realizing its punch line.

Keywords: Daniel Kehlmann, Tyll, humor, postirony, German-language contemporary literature.
\end{abstract}

In der Gegenwartsliteratur lässt sich eine fortschreitende Renaissance des Humors beobachten. ${ }^{1}$ So setzt auch Daniel Kehlmann in seinem Roman

1 Diese Annahme resultiert aus vor allem in der Gegenwartskultur zu beobachtenden Entwicklungen wie z. B. der Etablierung der Stand-up-Comedy im Deutschen Fernsehen, der stark durch humoristische Elemente gekennzeichneten Poetry-Slam-Kultur oder Kabarettisten, die zu Romanautoren werden, wie z. B. dem Satiriker Moritz Netenjakob mit seinem Roman Milchschaumschläger. Ein Café-Roman (Köln: KiWi-Verlag, 2017). Dies sind zwar punktuelle Erscheinungen, doch seit Jakob Hein und Jürgen Witte in ihrem Buch Deutsch und Humor. Geschichte einer Feindschaft (Köln: KiWi-Verlag, 2013) für mehr Humor in der deutschsprachigen Literatur plädierten, werden zunehmend auch humoristische oder satirische Werke mit Literaturpreisen gewürdigt. So wurde 2015 mit dem Deutschen Litera- 
Tyll (Rowohlt, 2017), nach den Prämissen der Neuen Deutschen Lesbarkeit, ${ }^{2}$ also einer Literatur, die Unterhaltung und Ernst miteinander verbindet, ${ }^{3}$ verschiedene Arten von Humor ein. ${ }^{4}$ Dabei befolgt er nicht die traditionellen Regeln des Komischen, sondern verstößt vielmehr gegen diese, womit er die Grenzen des Komischen auslotet, indem er unter anderem komische und ernste Elemente miteinander vermischt. So ist das Ziel des vorliegenden Beitrags, den Umgang Kehlmanns mit Humor und insbesondere Ironie zu untersuchen, sowie am Beispiel dieses Romans einige Überlegungen zu dem bisher wenig untersuchten Phänomen der Postironie zu präsentieren.

\title{
1. Struktureller Humor - an der Grenze zwischen Humor und Ernst
}

\author{
Das Ziel des Komischen ${ }^{5}$ besteht darin, beim Rezipienten Lachen oder
} zumindest ein Lächeln hervorzurufen. Dabei unterscheiden sich die literari-

turpreis unerwartet ein Werk ausgezeichnet, dessen Autor zwar kein dezidiert komischer Autor sei, doch Frank Witzels Die Erfindung der Roten Armee Fraktion durch einen manisch depressiven Teenager im Sommer 1969 zeigt eine starke humoristische Grundierung. Erinnert sei auch an den Ingeborg-Bachmann-Preis 2008, der an Tilman Rammstedt ging, und an die Vergabe des Bremer Literaturpreises 2013 an Wolf Haas, der wiederum drei Jahre später mit dem internationalen Jonathan-Swift-Preis für Satire und Humor (zum ersten Mal 2015 verliehen) gekürt wurde.

2 Die Prämissen der Neuen Deutschen Lesbarkeit wurden u. a. durch Daniel Kehlmann in den späten Neunzigerjahren mitentwickelt. Darunter sind u. a. solche Forderungen an den Text zu fassen, wie die Simplifizierung des Erzählens bei seiner gleichzeitigen Verkomplizierung, eine zwischen E- und U-Literatur zu verortende Ästhetik, eine Hinwendung zu jeder Art von Ironie, der fallweise Verzicht auf Action, Plot Points und Pointen, die Erzeugung von Spannung durch Rückbesinnung auf allerhand Techniken, Leerstellen und Pausen, das Spielerische, doch mit Sendungsbewusstsein. Vgl. hierzu: Matthias Politycki, „Kalbfleisch mit Reis! Die literarische Ästhetik der 78er-Generation," in Matthias Politycki, Die Farbe der Vokale. Von der Literatur, den 78ern und dem Gequake satter Frösche (München: Luchterhand, 1998), 34-44.

3 Vor allem in Hinblick auf die Komik lässt sich die Trennung zwischen Hoch- und Populärkultur (E und U) nicht mehr aufrechterhalten. Vgl. Sefan Balzter, Wo ist der Witz? Techniken zur Komikerzeugung in Literatur und Musik (Berlin: Erich Schmidt Verlag, 2013). Vgl. auch Sven Hanuschek, Laurel \& Hardy. Eine Revision (Wien: Zsolnay, 2010).

4 Zur Verarbeitung der Neuen Deutschen Lesbarkeit bei Kehlmann, insb. in seinem Roman Die Vermessung der Welt vgl. Benjamin Schaper, Poetik und Politik der Lesbarkeit in der deutschen Literatur (Heidelberg: Universitätsverlag Winter, 2017), insb. 148-182.

5 Einen guten Überblick über verschiedene Ansätze zum Komischen in der Literatur seit der Antike liefert András Horn, Das Komische im Spiegel der Literatur. Versuch einer systematischen Einführung (Würzburg: Könighausen \& Neumann, 1988). Zum Begriff und den Techniken des Komischen siehe: Stefan Balzter, Wo ist der Witz? Techniken zur Komikerzeugung in Literatur und Musik (Berlin: Erich Schmidt Verlag, 2013). 
sche und die außerliterarische Komik trotz der gleichen Grundstruktur in ihren Wirkungsbedingungen insofern, als sich die außertextuelle Komik meist spontan einstellt, wogegen ihre ästhetische Verarbeitung in der Literatur kalkuliert und entsprechend kontextualisiert wird. Daher wird im Weiteren unter Komik bzw. Humor die Summe literarischer Techniken verstanden, die auf den Effekt zielen, beim Rezipienten Lachen oder Schmunzeln hervorzurufen. Eine solchermaßen verstandene Komik (bzw. Humor) dient als „Oberbegriff zu einer ganzen Reihe von Verfahren, seien diese dramatischer Natur (Situations-, Handlungs- und Charakterkomik), rhetorischer Provenienz (Wortspiele, Ironie, Parodie, Pastiche usw.), motivischer Natur (etwa groteske Figuren, Wesen, Gegenstände) oder anderer, noch zu bestimmender Art."6 Zwar liegt das Komische grundsätzlich im Auge des Betrachters, dennoch lässt sich eine Form der Normverletzung als Grundvoraussetzung zur Entstehung der gewünschten Wirkung festhalten: „Der komische Gegenstand verletzt die Vorgabe für einen als normal angesehenen Fall, er weicht in signifikanter Weise von dem sozial Akzeptierten ab; insofern hat das Komische immer eine (implizite oder explizite) gesellschaftliche Dimension. ${ }^{\text {"7 }}$ Daher wird als konstitutiv für die Komik oft der Kontrast oder eine Inkongruenz, das heißt ein Zusammentreffen scheinbar disparater Elemente, angesehen. ${ }^{8}$ Da es dennoch keine Wirkungsgarantie gibt, liefern komische Texte oft in impliziter oder expliziter Weise den normativen Rahmen mit, indem sie klar die Gattung (Komödie) bezeichnen oder bestimmte Elemente oder Figuren einsetzen, die im kollektiven Bewusstsein der Rezipienten bereits mit dem Komischen (bzw. Humor) konnotiert sind. Eben dies nutzt Daniel Kehlmann, wenn er in Tyll den Narren Eulenspiegel auftreten lässt. Außerdem behandelt er in seinem Roman zwei Themen (Schwank und Krieg) sowie zwei Epochen (Mittelalter und frühe Neuzeit), die zueinander in einem grundsätzlichen Widerspruch stehen. Diese strukturelle Inkongruenz ${ }^{9}$ kann durch einen plötzlichen Wechsel, das sog. Kipp-Phänomen ${ }^{10}$, das heißt ein Überraschungsmoment, gesteigert werden.

6 Niklas Bender, Die lachende Kunst. Der Beitrag des Komischen zur klassischen Moderne (Freiburg i. Br./Berlin/Wien: Rombach Verlag, 2017), 26.

7 Bender, Die lachende Kunst. Der Beitrag des Komischen zur klassischen Moderne, 27.

8 Hajo Diekmannshenke, Stefan Neuhaus und Uta Schaffers, „Vorwort,“ in Das Komische in der Kultur, hrsg. v. Hajo Diekmannshenke, Stefan Neuhaus und Uta Schaffers, unter Mitarbeit von Eva Stubenrauch (Marburg: Tectum Verlag, 2015), 11.

9 Eine gute Übersicht über die (zum Teil entgegengesetzten) Positionen zur Natur der Inkongruenz liefert Niklas Bender, Die lachende Kunst. Der Beitrag des Komischen zur klassischen Moderne (Freiburg i. Br. - Berlin - Wien: Rombach Verlag, 2017), 31-32.

10 Vgl. dazu Wolfgang Iser, „Das Komische: ein Kipp-Phänomen“, in Das Komische, hrsg. v. Wolfgang Preisendanz und Rainer Warning (München: Wilhelm Fink Verlag, 1976), 398-402. 
Damit das Komische seine Wirkung entfalten kann, muss darüber hinaus eine Distanz zwischen dem komischen Faktum und dem Betrachter bewahrt werden, was nach Stierle unter anderem durch die Betrachtung der komischen Situation außerhalb ihres kausalen Kontextes zu erreichen ist. Denn Gefühle, die sich nach der Bewusstwerdung der möglichen Folgen der komischen Situation einstellen können (z. B. Mitleid), verhindern die komische Wirkung. ${ }^{11}$ Es lassen sich zwei Formen dieser Distanz unterscheiden: die komische Relation, also eine emotionale Distanz zwischen Betrachter und Gegenstand, sowie der komische Gegenstand selbst, das heißt die Isoliertheit des Komischen innerhalb der Romanwelt. Mit anderen Worten: Damit der Gegenstand komisch wirkt, darf keine emotionale Nähe zwischen dem Betrachter und dem Gegenstand entstehen: „Wenn ein komischer Gegenstand hinsichtlich seiner lächerlichen Seite zu stark kontextualisiert, zu sehr mit Vor- und Nachgeschichte ausgestattet wird, dann verhindert das die komische Wirkung." ${ }^{2}$ Bereits in der klassischen Moderne lassen sich Tendenzen beobachten, welche die komische Wirkung bewusst mindern, wie die Aufhebung der Dekontextualisierung des komischen Gegenstandes, die Aufhebung der komischen Distanz zwischen Betrachter und Kunstwerk, Betonung der Normverletzung oder der Inkongruenz, ästhetische Vermischung des Komischen beispielsweise mit dem Ernsten. ${ }^{13}$ All diese Elemente sind auch in Tyll vertreten, was im Weiteren anhand einiger ausgewählter Beispiele vorzuführen ist.

Die ästhetische Vermischung des Komischen mit dem Ernst ist unter anderem an der kontrastiven Komposition des Romans zu beobachten. So beginnt der Roman zwar mit Tylls Schuhe-Streich, doch schon wenige Seiten nach diesem Schwank wechselt plötzlich die Erzählperspektive vom auktorialen Erzähler in den Pluralis Auctoris rüber, sodass der gerade noch belustigte Rezipient unmittelbar in die Handlung des Krieges miteinbezogen wird: „Und ein gutes Jahr später kam der Krieg doch zu uns. Eines Nachts hörten wir es wiehern, und dann lachte es draußen mit vielen Stimmen, und schon hörten wir das Krachen der eingeschlagenen Türen, und bevor wir noch auf der Straße waren, mit nutzlosen Heugabeln oder Messern bewaffnet, züngelten die Flammen. "14 Diese ästhetische Vermischung beider Phänomene (Ernst und Humor) ist gleichermaßen auf der Wortebene zu beobachten (man hörte es wiehern und lachen). Und kaum einer der gerade noch vorge-

11 Vgl. Karlheinz Stierle, „Komik der Handlung, Komik der Sprachhandlung, Komik der Komödie," in Das Komische, hrsg. v. Wolfgang Preisendanz, und Rainer Warning (München: Wilhelm Fink Verlag, 1976), 251.

12 Bender, Die lachende Kunst. Der Beitrag des Komischen zur klassischen Moderne, 33.

13 Bender, Die lachende Kunst. Der Beitrag des Komischen zur klassischen Moderne, 38.

14 Daniel Kehlmann, Tyll. Roman (Reinbeck bei Hamburg: Rowohlt, 2017), 27. 
stellten Dorfbewohner überlebt. Die emotionale Involviertheit des Rezipienten und seine Identifikation mit dem vorgeführten Dreißigjährigen Krieg wird außerdem dadurch verstärkt, dass die Erzählstimme diesen Krieg durch einen beliebigen ersetzen lässt: „Wir aber erinnern uns, auch wenn keiner sich an uns erinnert, denn wir haben uns noch nicht damit abgefunden, nicht zu sein. Der Tod ist immer noch neu für uns, und die Dinge der Lebenden sind uns nicht gleichgültig. Denn es ist alles nicht lang her." ${ }^{15}$ Intendiert ist damit möglicherweise eine Aktualisierung des Zweiten Weltkrieges, zu dem viele der gegenwärtigen Rezipienten aufgrund ihrer Familiengeschichte noch einen persönlichen Bezug haben. Somit wird der emotionale Ernst des Lesers wiederhergestellt.

Die Aufhebung der Dekontextualisierung des komischen Gegenstandes bzw. die Erschaffung eines Kontexts für diesen Gegenstand wird bei Kehlmann unter anderem dadurch erreicht, dass Tyll eine Vorgeschichte bekommt. Seine Mutter, eine einfache Müllerstochter, und sein Vater, ein wissbegieriger Autodidakt, der wegen seines Wissensdrangs der Hexerei beschuldigt und von der Inquisition zum Tode verurteilt wird, erschaffen eine psychische Motivierung für Tylls späteren Lebenslauf als Spaßmacher. ${ }^{16}$ Das Wissen um Tylls schwierige Kindheit erzeugt beim Rezipienten unter Umständen Mitleid, was wiederum das Aufkommen von Humor verhindert. Eine strukturelle Verbindung von humoresken Elementen mit dem Gefühl von Mitleid wird an einer weiteren Textstelle noch deutlicher, und zwar als Tyll bei einer Mehlauslieferung eine Nacht allein im Wald verbringt. Als er von seinem Vater wiedergefunden wird, sitzt der Junge mit einem Eselskopf auf einem Baum. Nach dem Grund dieser Handlung gefragt, antwortet er: „'Die Zeit war lang', sagt der Junge. 'Niemand ist gekommen. Es war nur ein Spaß. Und die Stimmen! Ein großer Spaß.'"17 Dieses Ereignis beeinträchtigt sichtlich seine Gesundheit, denn er „kichert im Schlaf, seine Haut fühlt sich heiß an. "18 So wird das Lachen bzw. Kichern und Spaß mit weniger lustigen Elementen neu verknüpft. Mit dieser Erzählstrategie wird aber nicht nur das Humorempfinden des Rezipienten beeinflusst, sondern vor allem die nötige komische Distanz zwischen dem Gegenstand - hier Tyll - und seinem Betrachter aufgehoben. Diese Distanz wird außerdem dadurch verkürzt, dass Tyll mit einem dem heutigen Rezipienten vertrauten Wertesystem ausge-

15 Kehlmann, Tyll. Roman, 29.

16 Seine Streiche können hier als Versuch einer psychischen Verarbeitung der Traumata aufgefasst werden.

17 Kehlmann, Tyll. Roman, 82

18 Kehlmann, Tyll. Roman, 82. 
stattet wird, wie etwa dem Drang nach Individualität ${ }^{19}$ oder dem Trachten nach der großen Welt und individueller Freiheit. ${ }^{20}$

Die ästhetische Vermischung des Humorvollen mit dem Ernsten ist in Tyll gleichermaßen auf der Makroebene erkennbar, und zwar durch den Einsatz von Themen und Figuren, die im kollektiven Bewusstsein diesen beiden Kategorien zuzuschreiben sind, worauf der Text ausdrücklich hinweist: „Auf dem Kutschbock aber saß ein Mann, den wir erkannten, obgleich er noch nie hier gewesen war, und als die Ersten sich erinnerten und seinen Namen riefen, erinnerten sich auch andere." ${ }^{21}$ Dass es sich bei Tyll Eulenspiegel eben um eine Figur handelt, die fest mit Humor konnotiert ist (und so gelesen werden soll), wird im Text sogar thematisiert: „Kaum sprach sie von dem berühmten Spaßmacher, musste sie lächeln. Und so war es immer, schrieb der dicke Graf fünfzig Jahre später, alle schienen Bescheid zu wissen." ${ }^{22}$ Und während Tyll mit dem Komischen konnotiert ist, sind der Dreißigjährige Krieg sowie die Geschichte des Winterkönigs und dessen Untergang eindeutig der Sphäre des Ernstes zuzuordnen.

Der Winterkönig wird von einem unbekannten Erzähler eingeführt: „Als es Abend wird, sitzen sie auf dem Boden und hören dem Erzähler zu. Er spricht vom armen König Friedrich zu Prag, dessen Herrschaft nur einen Winter gedauert hat, bis ihn des Kaisers mächtiges Heer vertrieben hat, und liegt sie darnieder, die stolze Stadt, und wird sich nie erholen." ${ }^{23}$ Nur wenige Seiten nach dieser Stelle beginnt ein neues Kapitel, dessen Titel „Zusmarshausen“ an eine Schlacht am 17. Mai 1648 erinnert, die letzte große Feldschlacht des Dreißigjährigen Krieges (1618-1648), der in den Roman als eine Erinnerung des Grafen Martin von Wolkenstein eingeführt wird, „als Seine Majestät ihn im letzten Jahr des Krieges ausgeschickt habe, den berühmten Spaßmacher zu finden. ${ }^{24}$

Ist es schon Groteske (und somit Humor), ${ }^{25}$ dass sich der dicke Graf in seinem Reise- und Kriegsbericht an den platzenden Kopf einer erschossenen

19 „Das Seil. Etwas können, das kein anderer kann. Das ist gut.“ Kehlmann, Tyll. Roman, 51.

20 "Denk an den alten Spruch. Was Besseres als den Tod findest du überall.", Kehlmann, Tyll. Roman, 18. Diese Worte sind außerdem ein direktes Zitat aus dem Märchen Die Bremer Stadtmusikanten der Gebrüder Grimm, in dem ein entlaufener Esel unterwegs nach Bremen ist, um dort Stadtmusikant zu werden.

21 Kehlmann, Tyll. Roman, 8.

22 Kehlmann, Tyll. Roman, 198.

23 Kehlmann, Tyll. Roman, 176.

24 Kehlmann, Tyll. Roman, 183.

25 „Das Groteske ist ein Effekt der ,Spannung' zwischen den der Rezeption zugrundeliegenden, die Erwartungen des Rezipienten determinierenden kulturellen Kategorien und Normen sowie einem Gegenstand, der ihnen inadäquat ist und daher die auf ihnen beruhenden Erwartungen enttäuscht." Peter Fuß, Das Groteske. Ein Medium des kulturellen Wandels (Köln/Weimar/Wien: Böhlau Verlag, 2001), 81. 
Gans viel besser erinnert, als an alles andere?26 Die Beschreibung des bei diesem Anblick entstandenen Ekels wird mit der Darstellung zerstörter Dörfer und hungriger Bettler kontrastiert. Anschließend berichtet der dicke Graf von der „Kameradschaft der Männer, die einer Gefahr entgegengehen im Wissen, dass ebendiese Gefahr sie entweder töten oder fürs Leben in Freundschaft verbinden wird. ${ }^{27}$ Auch hier ruft der Roman ambivalente Gefühle hervor, wenn er den Krieg zu einer Kameradschaft der Männer in schwierigen Zeiten umdeutet, was durchaus eher an Spaß grenzt als an den Tod. Nur wenige Seiten nach der Schilderung der getöteten Gans treffen der dicke Graf und seine Begleiter tatsächlich auf den ersten Toten und dann regelmäßig auf „Leichenhaufen.“ ${ }^{28}$ Wie an diesen wenigen Beispielen ersichtlich, wird die Erfahrung des Kriegs in Tyll oft bagatellisiert oder sogar ins Positive verkehrt und als ein fröhliches Ereignis vorgeführt, wie etwa bei der Beschreibung der Rückkehr nach Wien: „Da hörten sie Musik. Sie hielten den Atem an und horchten: Trompeten und Trommeln, eine fröhliche Marschmusik, die in die Beine ging. Der dicke Graf bemerkte, dass seine Schultern im Takt zuckten." ${ }^{29}$

An Groteske grenzt auch die Aussage des dicken Grafen, er könne den Krieg nicht gut erzählen: „Lassen wir das, man kann es [die Erfahrung des

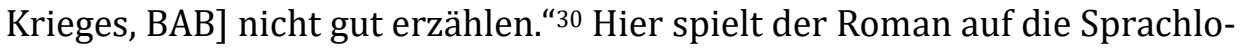
sigkeit gegenüber der Kriegserfahrung an, ${ }^{31}$ die in diesem Roman meist nur

26 „Und obgleich der dicke Graf bald darauf noch viel mitansehen würde, sollte er sein Lebtag nicht vergessen, welch ein Schrecken ihn bis ins Innerste durchfuhr, als der Kopf des Vogels platzte. Etwas daran war fast unbegreiflich - wie schnell das ging, wie sich von einem Moment zum nächsten ein fester kleiner Kopf in ein Aufspritzen und in nichts verwandelte und wie das Tier noch ein paar Watschelschritte machte und dann zu einem weißen Gebilde zusammensank, in einer wachsenden Pfütze Blut. [...] Aber natürlich vergaß er nicht, und als er sich ein halbes Jahrhundert später bei der Abfassung seines Lebensberichtes an diese Reise erinnerte, war es das Bild des zerplatzenden Gänsekopfs, das an Deutlichkeit alles andere überstrahlte." Kehlmann, Tyll. Roman, 189.

27 Kehlmann, Tyll. Roman, 192.

28 Vgl. Kehlmann, Tyll. Roman, 197.

29 Kehlmann, Tyll. Roman, 214.

30 Kehlmann, Tyll. Roman, 217.

31 Walter Benjamin zufolge sind die Kämpfer aus dem Ersten Weltkrieg verstummt zurückgekehrt, womit er die verbreitete Auffassung vertritt, dass die Soldaten über ihre Kriegserfahrungen nicht sprechen können. Vgl. hierzu: Walter Benjamin, „Der Erzähler. Betrachtungen zum Werk Nikolai Lesskows“, in Gesammelte Schriften II, 2, hrsg. v. Rolf Tiedemann und Hermann Schweppenhäuser (Frankfurt am Main: Suhrkamp, 1977), 438-465. Zum Erzählen vom Krieg in der Frühen Neuzeit vgl. Maren Lorenz, „Tiefe Wunden, Gewalterfahrung in den Kriegen der Frühen Neuzeit", in Gesellschaft - Gewalt - Vertrauen. Jan Philipp Reemtsma zum 60. Geburtstag, hrsg. v. Ulrich Bielefeld u. a. (Hamburg: HIS Verlagsges. $\mathrm{mbH}, 2012$ ), 332-354. Kriegserfahrungen erzählen, hrsg. v. Jörg Rogge (Bielefeld: transkript Verlag, 2016). 
auf eine ästhetische Kategorie begrenzt wird, wie zum Beispiel beim Anblick einer explodierenden Brücke: ${ }^{2}$ „Wie schön, dachte der dicke Graf und schämte sich sofort und dachte gleich darauf noch einmal, wie zum Trotz: Doch, das war schön. “33

Auch die Schilderung der weiteren Ereignisse ist der Groteske zuzuordnen:

\begin{abstract}
Während er [der dicke Graf, BAB] noch seine Augen anstrengte, um zu begreifen, was er sah, hörte er ein Geräusch, wie er es noch nie vernommen hatte, ein Schreien aus der Luft. Franz Kärrnbauer warf sich vom Pferd, überrascht schaute der dicke Graf $\mathrm{zu}$, wie er durchs Gras rollte, und fragte sich, ob er nicht das Gleiche tun sollte, aber das Pferd war hoch und der Boden voll harter Steine. Da kam Karl von Doder ihm zuvor. Er sprang aber nicht in eine Richtung, sondern in zwei, so als hätte er sich nicht entscheiden können und von zwei Möglichkeiten beide ergriffen. Zunächst dachte der dicke Graf, dass er wohl träumen müsse, doch dann sah er, dass Karl von Doder tatsächlich an zwei Orten lag: der eine Teil rechts, der andere links vom Pferd, und der auf der rechten bewegte sich noch. ${ }^{34}$
\end{abstract}

Für die Beschreibung der auseinandergerissenen Weggefährten wählt der Autor einen naiven Erzähler. Doch der wahre Witz dieser Beschreibung liegt letztendlich nicht in ihrer grotesken Darstellung, sondern vielmehr in der Tatsache, dass der dicke Graf, wie er gesteht, seine Beschreibung dem Simplicissimus von Grimmelshausen entnommen hat, der wiederum seine Kriegsbeschreibung abgeschrieben hat, und zwar aus einer Beschreibung im Roman, „dessen Autor nie im Leben bei einer Schlacht dabei gewesen war.“"

Ein weiteres Beispiel für die ästhetische Vermischung von Ernst und Humor ist die Geschichte des Winterkönigs. Sie beginnt mit zahlreichen belanglosen Einzelheiten, welche die Ernsthaftigkeit des Königtums mindern. Allem voran steht die Feststellung, dass die Weinvorräte erschöpft seien und man ab sofort nur noch Milch trinken müsse. Da der Schwedenkönig die Prinzessin Elisabeth Stuart (im Roman stets Liz genannt) nicht heiraten möchte,36 wird sie mit Friedrich V., dem „armen Friedrich,"37 vermählt. Durch Einsatz dieser Stilmittel (Diminutive und Kosenamen) erscheint die Königsfamilie dem Rezipienten nicht nur zugänglicher und menschlicher, sondern es wird gezielt ein Gefühl von Mitleid erweckt. Zudem lässt sich an

32 Kriegserfahrungen sind für die frühe Neuzeit und die Neuzeit im Gegensatz zum Spätmittelalter relativ gut erforscht. Im Mittelalter fehlt es an den Berichten der Augenzeugen. Denn die meisten Texte entstanden unter Verwendung von Berichten von Augen- und Ohrenzeugen. Vgl. Jörg Rogge, „Kriegserfahrungen erzählen - Einleitung“, in Kriegserfahrungen erzählen, hrsg. v. Jörg Rogge (Bielefeld: transkript Verlag, 2016), 9-30.

33 Kehlmann, Tyll. Roman, 218.

34 Kehlmann, Tyll. Roman, 219.

35 Kehlmann, Tyll. Roman, 224.

36 Kehlmann, Tyll. Roman, 230.

37 Kehlmann, Tyll. Roman, 230. 
dieser Stelle von einer Komik der Herabsetzung sprechen, die „dem Betrachter ein Gefühl der Überlegenheit [gibt], in dem er das Scheitern eines anderen erkennt." ${ }^{38}$ Dasselbe Verfahren wird eingesetzt, wenn Tyll den Winterkönig als „den dummen König"39 bezeichnet.

Auch die königlichen Aufgaben werden ins Lächerliche gezogen. So stellt ein Gespräch zwischen einem Untertanen und dem König den letzteren als einen unfähigen Herrscher dar, ${ }^{40}$ der nicht mal über die Kunst des Smalltalks verfügt. Um doch irgendetwas zu sagen, bemerkt er wie nebenbei, dass es heutzutage mehr Hexen gebe als je. Diese Bemerkung hat hier allerdings eine textkompositorische Funktion und ermöglicht den Sprung in das „Jetzt“ der Geschichte, also in die Zeit als Liz und Friedrich im Exil in den Niederlanden leben und Tyll Ulenspiegel ihr Hofnarr ist. Eben an dieser Stelle kreuzen sich beide Themen, wenn Tyll als das letzte Symbol des Königreichs fungiert: „Deshalb hatte man Narren, und selbst wenn man keinen Narren wollte, musste man einen zulassen, denn ohne Hofnarr war ein Hof kein Hof, und da sie und Friedrich kein Land mehr hatten, musste zumindest ihr Hof in Ordnung sein." ${ }^{41}$ Mit dieser Feststellung wird der Status des Narren über den des Königs erhöht. Denn ein Narr könne man auch ohne einen König sein, aber nicht umgekehrt.

Ein weiteres Beispiel für die ästhetische Vermischung des Komischen mit dem Ernsten ist die Tatsache, dass sich Tyll im Verlauf des Romans zu einem „weisen Narren“ entwickelt und somit selbst das Ernste repräsentiert. Darauf, dass die Figur Tylls in Kehlmanns Roman modifiziert wird, weist sogar der Roman selbst hin, als Tyll von dem dicken Grafen abgeholt wird: „Karl von Doder legte dem dicken Grafen eine Hand auf die Schulter und flüsterte: 'Das ist er nicht.' [...] 'Ich glaube, das ist nicht der, den ich gesehen habe.' [...] 'Damals auf dem Jahrmarkt. Ich kann's nicht ändern. Ich glaube, er ist es nicht.'" 42 Dies lässt sich als ein Zeichen dafür interpretieren, dass die Figur des Narren in Tyll einer Transformation unterzogen wird, dass der Schalk in diesem Roman mit ernsthaften Elementen behaftet ist.

38 Wendelin Schmidt-Dengler und Klaus Zeyringer, „Komische Diskurse und literarische Strategien. Komik in der österreichischen Literatur - eine Einleitung“, in Komik in der österreichischen Literatur, hrsg. v. Wendelin Schmidt-Dengler, Johann Sonnleitner und Klaus Zeyringer (Berlin: Erich Schmidt Verlag, 1996), 12.

39 Vgl. Kehlmann, Tyll. Roman, 296.

40 Ein weiteres Beispiel für die Unfähigkeit des Königs ist folgende Feststellung Tylls: „Von mir gehört hat die kleine Majestät, die saublöde Majestät mit der goldenen Krone auf dem goldenen Thron, weil ich nach euch geschickt hab. Und hau mich nicht, ich darf das sagen, du kennst doch die Narrenfreiheit. Wenn ich die Majestät nicht saublöd nenne, wer soll das sonst tun? Einer muss es doch. Und du darfst nicht." Kehlmann, Tyll. Roman, 208-209.

41 „Ihn hätte sie einst heiraten sollen, nach Papas Plänen, aber er hatte sie nicht gewollt.“ Kehlmann, Tyll. Roman, 236.

42 Kehlmann, Tyll. Roman, 210. 
Am Ende des Romans werden beide Elemente - die Figur eines Narren, eines Gauklers und das Motiv des Krieges - auf groteske Weise miteinander verbunden, und zwar als von Ulenspiegels Einsatz als Mineur während der Belagerung von Brünn berichtet wird. ${ }^{43}$ Die ursprüngliche Bedeutung des Grotesken als eines Instruments der Kritik mithilfe von Scherzen ist im Laufe des 19. Jahrhunderts verloren gegangen, sodass das Groteske heutzutage hauptsächlich vulgär-komisch wirkt, ohne jedoch dabei sichtbare Kritik an der Wirklichkeit auszuüben. Das wesentliche Merkmal des Grotesken, nämlich die Verzerrung der Realität, ist dennoch bei Kehlmann klar wahrnehmbar. Insbesondere im Kapitel „Im Schacht“, wo sich das Humorvolle und das Unheimliche miteinander verbinden. Die Realität - Tyll wurde zusammen mit einigen Soldaten im Schützengraben verschüttet - und seine Erinnerungen an das Verhör der Inquisitoren, an seinen Esel Origenes, an den Winterkönig verschmelzen: „Gerade will Tyll antworten, aber auf einmal ist nicht mehr der Matthias neben ihm, sondern der Jesuit auf seinem Schemel, den er so deutlich sieht wie damals: Du musst die Wahrheit sagen, du musst uns erzählen, wie der Müller den Teufel gerufen hat, du musst sagen, dass du Angst hattest." ${ }^{4}$ Trotz der einsetzenden Verwirrung ist sich Tyll der Realität noch bewusst: „Doch der Jesuit ist nicht hier, Tyll weiß das, nur die zwei Mineure sind hier, und der Pirmin drüben auf dem Waldweg, gerade haben sie ihn liegen gelassen." 45 Wie es Tyll dennoch gelingt zu überleben, erfahren wir nicht, denn diese Geschichte bricht im Moment der größten Spannung ab, was mit der möglichen ästhetischen Wirkung zu erklären ist. Denn aus psychologischer Sicht könnte nun das Lachen einsetzen, und zwar als Ventil zum Spannungsabbau beim Rezipienten. Dass Tyll es überlebt, erfährt der Rezipient an einer anderen Stelle aus den Memoiren des dicken Grafen:

In seinem Buch berichtete der dicke Graf dann auch knapp von der Nacht im Wald, von der ihm der mit einem Mal gesprächig gewordene Narr von seiner Zeit am Hof des Winterkönigs in Den Haag erzählt hatte und davon, wie er drei Jahre zuvor bei der Belagerung von Brünn verschüttet worden war. Zuerst habe er es sich mit dem Stadtkommandanten verscherzt, wegen einer Bemerkung über dessen Gesicht, sodass der ihn zu den Mineuren gesteckt habe, ${ }^{46}$ und dann sei der Schacht über seiner Einheit eingestürzt, hier, die Narbe an der Stirn, die habe er davongetragen. Eingesperrt in der Finsternis sei er gewesen, tief drunten, kein Ausweg, keine Luft, doch dann die wundersame Rettung. Es sei eine unglaubliche und wilde Geschichte gewesen, schrieb der dicke Graf, und der Umstand, dass er danach abrupt das Thema

43 Nebenbei bemerkt erinnert Tylls Geschichte an die Figur aus Jaroslav Hašeks Roman Die Abenteuer des braven Soldaten Schwejk.

44 Kehlmann, Tyll. Roman, 414.

45 Kehlmann, Tyll. Roman, 415.

46 Aus der späteren Erzählung Tylls weiß der Rezipient, dass es sich hierbei um eine freie Entscheidung Tylls handelt. Vgl. Kehlmann, Tyll. Roman, 404. 
wechselte und nicht darauf einging, wie die Wunderrettung unter Brünn denn eigentlich vonstattengegangen war, sollte später die Ratlosigkeit und Wut so mancher Leser wecken. ${ }^{47}$

Zusammenfassend lässt sich beobachten, dass Daniel Kehlmann in Tyll mehrere ästhetische Verfahren einsetzt, welche die Grenzen des Humors zu erproben scheinen und oft die mögliche Wirkung aufheben. Dies erreicht der Autor beispielsweise dadurch, dass er humorvolle Elemente mit Ernst oder sogar mit dem Gefühl des Mitleids verbindet, humorvolle Situationen um einen Kontext erweitert, der die Distanz des Rezipienten zu den Ereignissen verringert, oder indem er ernste Situationen wie den Krieg auf groteske Art und Weise darstellt. Dieses Spiel mit den Grenzen des Humors ist allerdings nur möglich, insofern man sich solcher Elemente bedient, die im kulturellen Gedächtnis fest mit den Kategorien Humor oder Ernst verknüpft sind. Dabei ist zu beobachten, dass dieses Verfahren nicht die Rezeption der Figuren (Tyll) oder Ereignisse (Krieg) verändert. Beide lassen sich nach der erfolgten Lektüre trotz der im Text vorgenommenen Umdeutung unverändert in ihren ursprünglichen Kategorien zuordnen. Anders steht es um die königlichen Figuren Friedrich V. und Elisabeth, deren Wahrnehmung durch die Lektüre nachhaltig beeinflusst wird. Dies ist mit ihrer schwächeren Verankerung im (deutschsprachigen) kulturellen Bewusstsein zu erklären. ${ }^{48}$ So lässt sich anhand der Beispiele schlussfolgern, dass Humor im kulturellen Bewusstsein mit manchen Figuren oder Phänomenen dermaßen fest verbunden ist, dass eine kurzzeitige Umdeutung ihre Wahrnehmung nicht dauerhaft verändern kann.

Könnte man bei Kehlmann dennoch von einer retroaktiven Rückprojektion einer Autorenperspektive in den Text der Vergangenheit sprechen? Jorge Luis Borges thematisiert in seinem Essay „Kafka und seine Vorläufer“ dieses zeitparadoxale Phänomen, dem zufolge alle AutorInnen ihre Rezipienten dazu bringen, gewisse Texte oder Figuren mit anderen Augen zu sehen. Die Arbeit des Autors „modifiziert unsere Auffassung von Vergangenheit genauso, wie sie die Zukunft modifiziert," 49 sodass ein alter Text neu ausgerichtet wird. Wie sich nun der Blick auf Till Eulenspiegel durch die Lektüre Kehlmanns Roman verändert, ist in diesem Beitrag nicht zu beantworten. Denn eine hierfür notwendige Rezeptionsanalyse würde den Rahmen dieses Beitrags und seine Zielsetzung sprengen.

47 Kehlmann, Tyll. Roman, 224-225.

48 Dies liegt wohl daran, dass diese Figuren ein Teil eines fremden kulturellen Gedächtnisses sind. Eine Rezeptionsanalyse dieses Textes unter Berücksichtigung der nationalen Zugehörigkeit (hier der britischen) würde wahrscheinlich ein umgekehrtes Ergebnis liefern, und zwar ein unverändertes Bild des Königspaares Friedrich V. und Elisabeth.

49 Jorge Luis Borgers, „Kafka und seine Vorläufer“, in Jorge Luis Borgers, Inquisitionen (Frankfurt am Main: Suhrkamp, 1992), 120-121. 


\section{Der letzte Drache oder die Spielarten des (Post-)Ironischen}

Ironie ${ }^{50}$ ist kein Phänomen der Neuzeit, denn sie ist bereits in der griechischen Komödie um 400 v. Chr. nachweisbar. ${ }^{51}$ Sie wird nach Wolfgang Kayser vereinfacht wie folgt definiert: „Bei der Ironie ist das Gegenteil von dem gemeint, was mit den Worten gesagt wird."52 Als Figur der Rede und Technik rhetorischer dissimulatio bezeichnet die Ironie jene Art der Verstellung, „,bei der die Worte das Gegenteil des Gemeinten ausdrücken, der Tenor des Sprechens aber anzeigt, daß eine Diskrepanz zwischen dem gesprochenen Wort und dem intendierten Sinn besteht. " ${ }^{33}$ Ursprünglich hatte der Typus des Ironikers als Gegenteil des urbanen Denkers eine negative Konnotation, die auf Eiron zurückgeht, der als schlauer Fuchs seine Siege mithilfe der Verstellung erreicht und der zum stereotypen Charakter der griechischen Komödie wurde. ${ }^{54}$ Trotz dieser klaren Einordnung zeigte die Ironie jedoch bereits in der Antike eine gewisse Ausdifferenzierung. So unterschied Aristoteles in der Nikomachischen Ethik zwischen ihren zwei Erscheinungsformen: Während die Eironeia eine Untertreibung oder (falsche) Bescheidenheit bedeutet, bezieht sich die ebenfalls mit der Ironie verwandte Alazoneia auf Übertreibung und Prahlerei.55 Beide Formen der Ironie sind eine Art des Scherzens (d. h. des Komischen), wie Aristoteles in seiner Rhetorik bemerkt, doch während der Ironiker sich selbst amüsiert, sucht beispielsweise der Bomolochos, der der Alazoneia zuzuordnen ist, mit seinen Scherzen andere oder sich selbst auf Kosten von anderen zu belustigen. ${ }^{56}$ Die Figur der Verstellung wurde noch in den Werken der Renaissance und im Humanismus oft eingesetzt, wie dies unter anderem an der Figur des weisen Narren zu beobachten ist. Seit der Renaissance verliert die Ironie aber zugunsten von Allegorie und Metapher zunehmend ihre Bedeutung, bis sie mit der Wieder-

50 Eine grundlegende Einführung in das Phänomen der Ironie, einen historischen Rückblick sowie eine Einführung in ihre Textgestalt und Stilistik liefert: Marika Müller, Die Ironie. Kulturgeschichte und Textgestalt (Würzburg: Königshausen \& Neumann, 1995).

51 Vgl. Ernst Behler, „Ironie“, in Historisches Wörterbuch der Rhetorik, hrsg. v. Gert Ueding, mitbegründet v. Walter Jens, in Verbindung mit Wilfried Barner, Dietrich Briesemeister u. a., Bd. 4 (Tübingen: Hu-K, Max Niemeyer Verlag, 1998), 599.

52 Wolfgang Kayser, Das sprachliche Kunstwerk (Bern: Francke, 1969), (i. 0. 1948), 111-112.

53 Ernst Behler, Ironie und literarische Moderne (München, Paderborn u. a.: Ferdinand Schöning Verlag, 1997), 21-22.

54 Vgl. Behler, Ironie und literarische Moderne, 22-23.

55 Vgl. Edgar Lapp, Linguistik der Ironie (Tübingen: Gunter Narr Verlag, 2. Aufl., 1991), 20. Vgl. auch Aristoteles, Nikomachische Ethik, AR 1127a ff.

56 Aristoteles, Nikomachische Ethik, AR 496 b, 7. 
entdeckung des Mittelalters durch die Romantiker ${ }^{57}$ - in einer veränderten Form - einen neuen Höhepunkt erreicht.

Die moderne bzw. romantische Ironie bekundet sich nun in einem neuen literarischen Verhältnis zwischen dem Autor und seiner Leserschaft, wobei der Autor derjenige ist, der die Rolle der Verstellung übernimmt und spielerisch mit dem Text umgeht. ${ }^{58}$ Ein Beispiel hierfür liefert Friedrich Schlegels Gespräch über die Poesie. In diesem Text machen sich sechs Gesprächspartner zum Ziel, die Natur der Poesie zu ergründen. Die hier auftretende Ironie zeigt sich allerdings nicht in einer Verstellung der Gesprächspartner, sondern ist auf der Strukturebene des Textes zu finden, und zwar in einer Gesprächsführung, die keine endgültigen Meinungen und Standpunkte zulässt. ${ }^{99}$ Damit entwickelt Schlegel ${ }^{60}$ eine Ironie, die sich als ein neues Bewusstsein des Autors vom Spiel im Werk und über das Werk zeigt. ${ }^{61}$ Ein weiteres Beispiel für die romantische Ironie liefert Ludwig Tiecks dramatisiertes Kindermärchen Der gestiefelte Kater, ${ }^{62}$ in dem ständige Unterbrechungen des Handlungsverlaufs vorherrschen, was die theatralische Stimmung immer wieder aufs Neue zerstört. So lässt Tieck nicht nur das Publikum auf die Bühne treten, sondern sogar den Dichter selbst, der die Handlungen des

57 Der Begriff der romantischen Ironie wurde zwar in der Romantik als solcher definiert, diese Art der Ironie bezieht sich allerdings auf das romantische Zeitalter, wie das späte Mittelalter und die Renaissance, also die Literatur von Dante, Boccaccio oder Cervantes, von den Brüdern Schlegel und weiteren Romantikern bezeichnet wurde. Sie lässt sich daher auch schon vor der Epoche der Romantik nachweisen, z. B. in Lawrence Sternes Tristam Shandy oder auch im Simplicius Simplicimus von Grimmelshausen. Denn vor allem die Frühromantiker hatten noch kein Bewusstsein über ihre eigene Zugehörigkeit zu der später als Romantik bezeichneten Literaturepoche. Vgl. Behler, Ironie und literarische Moderne, 67-68.

58 „Sie erscheint als moderne Geisteshaltung, die sich zwar in ihrem literarischen Ausdruck, als Heraustreten des Autors aus seinem Werk, bis in das Mittelalter zurückverfolgen läßt, im romantischen Zeitalter aber erst als Ironie bezeichnet wurde und deshalb oft, im Gegensatz zur klassischen Figur, den Namen romantische Ironie erhielt." Behler, Ironie und literarische Moderne, 22.

59 Dies erinnert in der Struktur an postmoderne Romane, die ihre Figuren widersprüchlich konstruieren, sodass sie sich nicht eindeutig in einem binaren System, zwischen "gut" und "böse" kategorisieren lassen.

60 Er attestiert z. B. Goethes Roman Wilhelm Meisters Lehrjahre eine über dem ganzen Werk schwebende Ironie: „Man lasse sich also dadurch, daß der Dichter selbst die Personen und die Begebenheiten so leicht und so launig zu nehmen, den Helden fast nie ohne Ironie zu erwähnen, und auf sein Meisterwerk selbst von der Höhe seines Geistes herabzulächeln scheint, nicht täuschen, als sei es ihm nicht der heiligste Ernst." Friedrich Schlegel, II, 133.

61 Vgl. René Bourgeois, L'ironie romantique. Spectacle et jeu de Mme des Staël à Gérard de Nerval (Grenoble: Presses Univ., 1974), 15-20. Vgl. hierzu: Behler, Ironie und literarische Moderne, 45.

62 In seinem Werk suchte Tieck in einer satirischen Posse die zeitgenössischen Repräsentanten der literarischen Aufklärung in Deutschland zu verspotten. 
sprechenden Katers kommentiert. Solche Auftritte des Dichters, der seiner Leserschaft oder dem Publikum den Text erläutert, erfreuten sich in der Romantik großer Popularität, sodass hierfür eine eigene Bezeichnung entstand, und zwar die „Ironie des aus dem Stück Fallens“, wie sie von Brentano bezeichnet wurde. 63 Zusammenfassend lässt sich festhalten, dass sich die romantische Ironie „auf Seiten des Autors [äußert], der gewissermaßen aus seinem Werk heraustritt und dieses mit spöttischem Lächeln betrachtet oder sich mit seinem Leser auf selbstkritische Weise über das Dargestellte unterhält." ${ }^{4} \mathrm{Im}$ Wesentlichen geht es aber sowohl bei der rhetorischen als auch bei der romantischen Ironie um Reflexion über die Grenzen der Sprache. ${ }^{65}$

Ironie ist aufgrund der zu erbringenden Decodierungsleistung auf der inhaltlichen Ebene mit dem Witz und der Kritik verwandt, wobei sie sich von diesen durch ihre ästhetische Komponente unterscheidet. Außerdem muss sich der Rezipient bei der Ironie, anders als bei einem Witz, einen bestimmten Rezeptionsmodus erarbeiten, um zum Lachen zu gelangen. Idealerweise reicht die Wirkung der Ironie tiefer als nur zur Belustigung des Rezipienten, ${ }^{66}$ denn „in der Ironie wird das Lachen zum Reflexionsmedium.“ ${ }^{67}$

In der Gegenwartsliteratur ist Ironie - als verbale, situationale und dramatische Ironie - sowohl auf der Figuren- als auch der Handlungsebene ein beliebtes Stilmittel. Dabei ist die verbale Ironie nicht als eine bloße Umkehrung des Gesagten zu verstehen, sondern als Form der Relativierung der Aussagen, die durch Wiederholungen bestimmter Phrasen oder Über- und Untertreibung bis hin zum Sarkasmus erreicht wird. Situationale Ironie tritt auf, wenn die Bemühungen von Figuren zu anderen Resultaten führen als intendiert oder sogar genau die Resultate herbeiführen, die sie eigentlich hatten vermeiden wollen. Die dramatische Ironie ergibt sich aus der Diskrepanz zwischen Erwartungen oder Wissen der Leserschaft und der dargestellten Realität. So liegt sie beispielsweise vor, wenn der Rezipient über mehr Wissen verfügt als eine Romanfigur und daher das Handeln dieser Figur in Hinblick auf seine Konsequenzen besser einschätzen kann. ${ }^{68}$

63 Zitiert nach Behler, Ironie und literarische Moderne, 51.

64 Behler, Ironie und literarische Moderne, 66.

65 Vgl. Behler, Ironie und literarische Moderne, 68.

66 Vgl. Stefan Seeber, Poetik des Lachens. Untersuchungen zum mittelhochdeutschen Roman um 1200 (Berlin, New York: Walter de Gruyter, 2010), 118-120.

67 Seeber, Poetik des Lachens. Untersuchungen zum mittelhochdeutschen Roman um 1200, 121.

68 Der amerikanische Literaturwissenschaftler Dennis H. Green unterschied unter der Berücksichtigung der antiken Theorie und insbesondere in Bezug auf die mittelalterliche Ironie einige Ironiemarker, die es als eine Art Raster erlauben, die Ironie genauer zu erfassen. Zu den Ironiemarkern gehören beispielsweise Klassifizierung durch spezifisches beschreibendes Vokabular, wie z. B. spotten, oder eine explizite Kennzeichnung der Ironie durch 
Um Kehlmanns Umgang mit Ironie zu veranschaulichen, hier insbesondere die Verwendung der Postironie, soll im Weiteren auf zwei Episoden eingegangen werden: auf den letzten Drachen des Nordens und auf den sprechenden Esel.

Einer der Inquisitoren, die Tylls Vater überführen, Doktor Tesimond, interessiert sich für Drakontologie, die Lehre vom Wesen der Drachen. ${ }^{69}$ Bisher ist es ihm allerdings noch nicht gelungen, einen Drachen zu finden, denn

die Drachen seien unvorstellbar scheu und zu verblüffenden Kunststücken der Tarnung fähig. Man könne hundert Jahre suchen und doch nie in die Nähe eines Drachen kommen. Ebenso könne man hundert Jahre in unmittelbarer Nähe eines Drachen verbringen und ihn nie bemerken. [...] In seiner geliebten Heimat gebe es noch zwei Drachen, aber aufgespürt habe sie seit Jahrhunderten kein Mensch. ${ }^{70}$

Die hier eingesetzte dramatische Ironie besteht darin, dass der Rezipient genau weiß, dass die Tatsache, dass bisher keine Drachen gefunden wurden, kein Beweis für deren Tarnkünste sein kann, geschweige denn für ihre Existenz. Nicht überzeugend ist für den Rezipienten auch das angeführte Argument, die Existenz der Drachen sei außerdem „wegen der Wirksamkeit der Substitute" 71 belegt, aufgrund deren Kräuter oder Tiere ihre Heilkraft erhalten, wie zum Beispiel der Egerling: „durch seine Ähnlichkeit mit dem Drachen! Warum kann der Zinnober heilen, wenn nicht deshalb, weil er dunkelrot ist wie Drachenblut!"72

Während diese Verwendung der dramatischen Ironie den klassischen Stilmitteln zuzurechnen ist und daher keiner weiteren Ausführung bedarf, stellt das, was im Weiteren als Postironie bezeichnet wird, eine neuere, noch nicht fest etablierte Tendenz der Gegenwartsliteratur ${ }^{73}$ dar: Denn Kehlmann realisiert in Tyll die Pointe der vorangestellten dramatischen Ironie,

Figuren oder den Erzähler oder auch eine Bewertung der Figurenreaktion auf die ironische Rede, indem das Lachen oder auch sein Ausbleiben z. B. als eine Fehlreaktion eingeschätzt werden. Die Bewertung des Verhaltens durch die Figurenwahrnehmung birgt jedoch die Gefahr der Fehldeutung der ironischen Rede durch den Rezipienten, denn die Einschätzung des Lachens als unangemessen kann individuell stark variieren. Vgl. Seeber, Poetik des Lachens. Untersuchungen zum mittelhochdeutschen Roman um 1200, 115-116.

69 Vgl. Kehlmann, Tyll. Roman, 99.

70 Kehlmann, Tyll. Roman, 100.

71 Kehlmann, Tyll. Roman, 101.

72 Kehlmann, Tyll. Roman, 101.

73 U. a. versuchte eine neue Avantgarde, „Rich Kids of Literature“, in einem Manifest die Ultraromantik auszurufen und eine neue literarische Richtung zu etablieren, die ekstatisches Sprechen proklamiert. Alles sei in dieser literarischen Richtung nur eine Inszenierung und funktioniert nach dem Motto: „Show, don't tell.“ In dem Verständnis der Ironie durch RKoL wird Pose zum Kommentar über die Pose. Alles wird überzeichnet und ohne eine kritische Distanz dargestellt. 
wodurch er diese transzendiert. Um dies zu ermöglichen, wird der Rezipient an einer anderen Textstelle erneut daran erinnert, dass ein Beweis für die Existenz von Drachen eben ihre Unauffindbarkeit sei: „Ein Drache, den man gesichtet hat, wäre ein Drache, der über die wichtigste Dracheneigenschaft nicht verfügt - jene nämlich, sich unauffindbar zu machen. "Hier schmunzelt der Rezipient womöglich noch, doch einige Seiten später wird er eines Besseren belehrt, als er von dem Erzähler vom Tod des letzten Drachen erfährt: „Im selben Jahr starb in der Holsteinischen Ebene der letzte Drache des Nordens. Er war siebzehntausend Jahre alt, und er war es müde, sich zu verstecken. " ${ }^{74}$ Eben mit der detaillierten Beschreibung des Todes des Drachen und der Information, dass sich ein Drache (womöglich in heilende Pflanzen oder Tiere?) verwandelt, wird die (Humor erzeugende) Pointe, nämlich die Tatsache, dass es keine Drachen gibt und ihre Nicht-Auffindbarkeit kein Beweis für ihre Existenz ist, realisiert. Dieses Verfahren soll im Weiteren als Postironie bezeichnet werden.

\section{Der sprechende Esel und die Postironie}

Ein weit raffinierteres Beispiel für dieses Verfahren stellt in Tyll der Esel dar. ${ }^{75}$ Denn Kehlmann steigert hier die Ironie aus dem Originaltext von Hermann Bote zur Ironie der Ironie bzw. der Postironie, indem er die Pointe der Originalgeschichte realisiert, wenn nicht gar potenziert. Mit diesem Verfahren wird die Ironie transzendiert, was sich mit einem Blick auf den Originaltext belegen lässt. Denn bei Kehlmann lernt der Esel statt Lesen (rezeptive Handlung) (scheinbar erfolgreich) das Sprechen (produktiv). Berücksichtigt man zudem die Konnotationen des Namens des Esels (Origenes), wird die Pointe nicht nur realisiert, sondern sogar übertroffen.

Kehlmanns Esel rekurriert nämlich auf die 29. Historie, Wie Eulenspiegel in Erfurt einen Esel in einem alten Psalter lesen lehrte, aus dem mittelalterlichen Geschichtenband Till Eulenspiegel von Hermann Bote: Als Till in Erfurt ankommt, beratschlagen die Gelehrten der hiesigen Universität darüber, mit welchen Aufgaben sie ihn betrauen sollten, damit sie nicht wie ihre Kollegen in Prag von Till lächerlich gemacht würden. „Und sie beschlossen, daß sie

74 Kehlmann, Tyll. Roman, 392.

75 Die nachfolgende Interpretation stellt selbstverständlich nur eine der möglichen Auslegungsvarianten des Textes dar. So konstatiert beispielsweise Joachim Rickes in seinem Beitrag zu Kehlmanns Ungewissheitspolitik, dass es in Tyll zwei Esel gebe, die eine poetologisch wichtige Rolle spielten, und zwar als Ausdruck von Kehlmanns spezifischer Darstellungskunst - der „Ungewissheitspoetik“. Vgl. Joachim Rickes, „Der Esel ist nicht der Esel. Zu Daniel Kehlmanns Ungewissheitspoetik in Tyll“, Sprachkunst, Nr. 49 (2018): 73-86. 
Eulenspiegel einen Esel in die Lehre geben wollten, denn es gibt viele Esel in Erfurt, alte und junge. "76 Eulenspiegel nimmt die Herausforderung an, doch er brauche Zeit, „weil es [der Esel] eine des Redens unfähige und unvernünftige Kreatur sei." So bekommt er hierfür 20 Jahre Zeit und die gewünschte Summe an Geld im Voraus ausbezahlt. Nun legt er dem Esel ein Psalmenbuch in seine Futterkrippe. „Und zwischen jedes Blatt legte er Hafer. Dessen wurde der Esel inne und warf um des Hafers willen die Blätter mit dem Maul herum. Wenn er dann keinen Hafer mehr zwischen den Blättern fand, rief er: 'I-A, I-A!'.“77 Als Till Eulenspiegel dies bemerkte, holte er den Rektor der Universität, um ihm die Ergebnisse seiner Arbeit vorzuführen. Er gab dem Esel ein neues Buch. Dieser blätterte auf der Suche nach Hafer zwischen den Seiten. „Als er nichts fand, begann er mit lauter Stimme zu schreien: 'I-A, I-A!' Da sprach Eulenspiegel: 'Seht, lieber Herr, die beiden Vokale I und A, die kann er jetzt schon; ich hoffe, er wird noch gut werden.'78

Bei Kehlmann ist die Idee, dem Esel das Sprechen beizubringen, nicht als ein Streich konzipiert, sondern dient vielmehr als Beweis für die Fähigkeiten der Tiere, denn „wenn man nur ein wenig geschickt sei, könne man jedes Tier zum Schwatzen bringen. Tiere seien klüger als Menschen, deswegen verhielten sie sich still, sie seien darauf bedacht, nicht wegen jedem Unsinn in Schwierigkeiten zu geraten. Sobald man einem Vieh aber gute Gründe biete, gebe es die Stille auf." Methode an wie schon sein historisches Vorbild:

So mache man es, man stecke Essen in ein Buch, und das lege man dem Tier wieder und wieder und wieder vor, mit Geduld und Stärke. Aus Gier blättere es die Seiten um und bekomme dabei mehr und mehr von der Menschensprache mit, nach zwei Monaten habe man Resultate. [...] Es lässt sich mit jedem [Tier] machen. Nur zu klein darf es nicht sein, sonst hört man seine Stimme nicht. ${ }^{80}$

Nach einiger Zeit vom Winterkönig nach den Ergebnissen gefragt, beteuert Tyll, „das I und das A hätten sie schon, und bereits übermorgen sei mit dem nächsten Laut zu rechnen"81.

76 Hermann Bote, Ein kurzweiliges Buch von Till Eulenspiegel aus dem Lande Braunschweig. Wie er sein Leben vollbracht hat. Sechsundneunzig seiner Geschichten, hrsg., in die Sprache unserer Zeit übertragen und mit Anmerkungen versehen v. Siegfried H. Sichtermann. Mit zeitgenössischen Illustrationen (Berlin: Insel Verlag, 19. Aufl., 2017), 90.

77 Bote, Ein kurzweiliges Buch von Till Eulenspiegel aus dem Lande Braunschweig. Wie er sein Leben vollbracht hat. Sechsundneunzig seiner Geschichten, 90-91.

78 Bote, Ein kurzweiliges Buch von Till Eulenspiegel aus dem Lande Braunschweig. Wie er sein Leben vollbracht hat. Sechsundneunzig seiner Geschichten, 92.

79 Kehlmann, Tyll. Roman, 291.

80 Kehlmann, Tyll. Roman, 291.

81 Kehlmann, Tyll. Roman, 293. 
Dass der Esel aber nicht wirklich spricht, wird dem Rezipienten bereits zu Beginn des Romans verraten, und zwar als sich Martha, ein junges Dorfmädchen, aus Neugier Tylls Theatertruppe nähert und von Tyll aufgefordert wird, einen Schluck Bier zu trinken, wobei sich Tyll nach den Einwohnern der Stadt erkundigt:

\footnotetext{
„Friedliche Leute, helfen einander, verstehen einander, mögen einander, solche Leute sind das?'

Sie nahm noch einen Schluck. 'Ja.'

'Na dann', sagte er.

'Wir werden sehen', sagte der Esel.

Vor Schreck ließ Martha den Humpen fallen.

'Das schöne Bier', sagte der Esel. 'Du saudummes Kind.'

'Man nennt das Reden mit dem Bauch', sagte Tyll Ulenspiegel. 'Kannst du auch lernen, wenn du möchtest.'

'Kannst du auch lernen', sagte der Esel. [...]

'Wir bringen dir alles bei', sagte der Esel. 'Ich und die Nele und die Alte und der Tyll. Und du kommst weg von hier. Die Welt ist groß. Du kannst sie sehen. Ich heiß nicht einfach Esel, ich hab auch einen Namen, ich bin Origenes.'“82
}

Bereits bei diesem Auftritt wird der Rezipient in Kenntnis gesetzt, dass es sich bei dem Esel nicht um ein sprechendes Tier handelt, sondern um ein Bauchrednerkunststück. Bemerkenswert ist außerdem, dass der Esel bereits zu diesem Zeitpunkt der Lektüre mit einigen Charaktereigenschaften ausgestattet und somit personifiziert wird. So tritt er hier in der Rolle eines Skeptikers auf, der an das Gute im Menschen nicht glaubt („Wir werden sehen“) und gleichzeitig als einer, der seine Meinung frei verkündet („Du saudummes Mädchen“).

Dramatische Ironie tritt unter anderem auf, wenn das Wissen des Rezipienten das Wissen der Figuren übersteigt. Durch diesen stillen Pakt zwischen Autor bzw. Erzähler und Rezipienten entsteht eine gewisse Spannung, die sich entweder durch die Erwartung einer Handlung oder durch die Angst vor den möglichen Konsequenzen für die Figuren äußert. Daher überrascht es nicht, dass die dramatische Ironie zu den beliebten Verfahren der Kriminalliteratur und der Horror-Filme gehört. Ein weiteres Beispiel für diese Ironie ist eine Situation, in der sich eine Figur als jemand anders ausgibt, doch deren eigentliche Identität dem Rezipienten bekannt ist. Ein ähnliches Phänomen tritt bei dem sprechenden Esel ein. Denn obwohl es dem Leser bewusst ist, dass ein Esel als Tier nicht sprechen kann, wird im Text abwechselnd behauptet, es handle sich hierbei selbstverständlich um die Bauchrednerkunst, und beteuert, das Tier könne tatsächlich reden. Dies wird beispielsweise in der Szene sichtbar, als eine Gruppe von Wissenschaftlern in Tylls Lager kommt.

82 Kehlmann, Tyll. Roman, 17. 
'Große Männer', sagte eine Stimme. 'Hier bei uns!'

Drüben bei den Zelten waren Leute, und etwas näher saß die Alte vor dem Waschbottich, aber direkt neben ihnen stand nur ein Esel. Das Tier blickte auf, senkte wieder den Kopf und zupfte Halme aus.

'Habt ihr das auch gehört?', fragte Fleming.

Olearius, der hinter ihm ausgestiegen war, nickte.

'Ich bin's', sagte der Esel.

'Dafür gibt es eine Erklärung', sagte Kircher.

'Und welche ist das?', fragte der Esel.

'Bauchrednerkunst', sagte Kircher.

'Stimmt', sagte der Esel. 'Ich bin Origenes.'

'Wo versteckt sich der Bauchredner?', fragte Olearius.

'Schläft', sagte der Esel. [...]

'Er schläft selten', sagte der Esel. 'Aber jetzt träumt er von euch.' Seine Stimme klang tief und so merkwürdig, als käme sie nicht aus einer Menschenkehle. [...]

'Das genügt', sagte Kircher. 'Der Bauchredner soll sich jetzt zeigen!' 'Bin hier', sagte der Esel. [...]

Es ist bloß ein Esel, dachte Kircher. Aber vor Wut ballten sich seine Fäuste. Jetzt verspotteten einen schon die deutschen Tiere! 83

Eine Weile später wollen die Besucher noch immer nicht daran glauben, der Esel habe tatsächlich mit ihnen gesprochen, und fragen nach:

'Eine Frage.' Fleming zeigte zu dem Esel hinüber, der ruhig Gras zupfte und dann und wann den Kopf hob und mit glanzlosen Tieraugen zu ihnen sah. 'Wer hat dem Esel -' 'Bauchrednerei.'

'Aber wo versteckt sich der Bauchredner?'

'Frag den Esel', sagte die Alte. ${ }^{84}$

Der Humor entsteht hier aus einem Paradoxon, denn einerseits wird den Figuren und dem Rezipienten nüchtern gesagt, dass es sich bei dem sprechenden Esel um ein Bauchrednerkunststück handelt, andererseits wird jedoch eine Illusion erzeugt, der Esel könne tatsächlich sprechen, was wiederum auf die zu Beginn des Beitrags erwähnte Normverletzung als Ursache für den Humor zurückzuführen ist. Dieses Spiel wird auf die Spitze getrieben, als Tyll und der Esel eine Nacht im Wald verbringen:

'Im Wald sind die Wölfe', hat der Esel gesagt, 'die haben Hunger, lass mich hier nicht stehen.' [...]

'Ich kann sie riechen, so nah sind sie. Du kletterst auf einen Baum, aber ich steh hier unten, und was tu ich, wenn sie kommen?'

'Du tust, was ich sage!'

'Aber wenn du was Blödes sagst?'

'Dann auch. Weil ich der Mensch bin. Ich hätte dir nie das Reden beibringen sollen.'

'Dir hätt man's auch nicht beibringen sollen, du sagst kaum was, das Sinn hat, und

83 Kehlmann, Tyll. Roman, 370-372.

84 Kehlmann, Tyll. Roman, 376. 
du jonglierst nicht mehr sicher. [...]'

Und da ist Tyll eben wütend auf den Baum, und der Esel ist wütend unten geblieben. [...] Die halbe Nacht hat er den Esel schimpfen gehört. [...] So ist Tyll eben eingeschlafen, und als er wieder aufgewacht ist, ist der Esel nicht mehr da gewesen. Die Wölfe sind nicht schuld, das hätte er schon gemerkt, wenn die gekommen wären; offenbar hat der Esel beschlossen, dass er es auch allein zu etwas bringen kann und keinen Bauchredner braucht. ${ }^{85}$

Diese Stelle kann als ein Beispiel für das grundlegende Merkmal der Poetik Kehlmanns gelten, für das Schwinden der Grenze zwischen der Wahrheit und der Imagination, zwischen der Ironie und dem Ernst. 86

Wie bereits erwähnt wurde, ist bei dieser Analyse der Name des Esels zu beachten, denn Origenes war ein christlicher Gelehrter und Theologe aus dem 1. Jh. n. Chr., dessen Vater während der Christenverfolgung unter Septimius Severus im Jahre 202 starb. ${ }^{87}$ Origenes lehrte zunächst elementare Grammatik und beschäftigte sich zunehmend mit der Exegese, mit deren Hilfe er die tiefere Bedeutung in der Heiligen Schrift zu entdecken suchte. Da er die Lehre vom dreifachen Schriftsinn aufstellte, gilt er als Begründer der allegorischen Auslegungsmethode, die den wörtlichen, den moralischen und den mystisch-allegorischen Sinn der Schrift unterscheidet.

Es gilt daher, nicht nur deren [der Schrift, BAB] historische Bedeutung (Literalsinn) zu erfassen, sondern auch ihre verborgenen Schätze zu erschließen (geistiger Schriftsinn; in De principiis nochmals unterteilt in psychischen und pneumatischen Sinn). Die im Bibeltext eingestreuten scheinbar widersinnigen Elemente haben die Funktion, die Suche nach dem geistigen Sinn anzustoßen. Dieser hebt den wörtlichen Sinn nicht auf oder entspringt der Willkür des Exegeten, sondern bezieht im Gesamthorizont der Bibel durch Allegorese (Anagogie) Einzelnes auf ein Netz signifikanter Ideen. ${ }^{88}$

85 Kehlmann, Tyll. Roman, 405-406.

86 Einen ähnlichen Kunstgriff benutzt Marc-Uwe Kling in seinen Känguru-Chroniken. Die Geschichte beginnt, als eines Tages vor der Tür des Erzählers ein Känguru steht, das sich als sein Nachbar ausgibt und ein paar Eier borgen möchte. Zwar verblüfft, dennoch händigt ihm der Erzähler die gewünschten Eier aus. Wenige Minuten später klingelt das Känguru erneut und borgt auch die weiteren Zutaten für sein Gericht. Als es nun am Ende noch gesteht, es habe ja gar keinen Herd, bietet ihm der Erzähler seine Küche an. Kurz darauf zieht das Känguru, das sich zudem als überzeugter Kommunist ausgibt, ins Wohnzimmer es Erzählers ein und verbleit dort mehrere Monate, wobei dieser für den Unterhalt und die geliebten Schnapspralinen seines neuen Mitbewohners aufkommen muss. Auch hier gibt es ein sprechendes Tier, das wie ein Mensch agiert.

87 Wenn angenommen wird, dass der Esel Origenes nur Tylls Stimme sei, ergibt sich hier eine Parallele zu Kehlmanns Tyll, dessen Vater in Kehlmanns Roman der Ketzerei und Hexerei bezichtigt und verurteilt wird, wobei seine Schuld nur im Wissensdrang bestand.

88 Clemens Scholten: „Origenes (AT),“ in Das wissenschaftliche Bibellexikon im Internet (WiBiLex), 2007, https://www.bibelwissenschaft.de/wibilex/das-bibellexikon/lexikon/sachwort/anzeigen/details/origenes-at/ch/0b1d6575c18a7f90f4aea21ace221413/. 
Würde man diesem Hinweis des Esels auf mehrfachen Sinn befolgen, welche Bedeutung ließe sich dem sprechenden Esel dann zuschreiben? Zwar scheint er die eigene Stimme zu sprechen, doch gleichzeitig nur das von sich zu geben, was der Bauchredner sagt: „Du tust, was ich sage!“89 - verkündet Tyll dem Esel. So erweist sich der Esel, trotz der starken Personifikation auf der Textebene, nicht als eine frei handelnde Figur. Als er sich am Ende seiner Episode entscheidet, in die Welt zu gehen (oder wurde er doch von den Wölfen zerfleischt?), wird seine Verselbstständigung verspottet.

Die durch die Namensgebung entstandene Konnotation nutzt Kehlmann außerdem dazu, bei den Rezipienten eine humoristische Wirkung zu erzielen. Diese erreicht er durch Kommentare, die nur mit entsprechendem Hintergrundwissen lesbar sind, wie etwa: „Der Esel spricht gut, aber er spricht ohne rechten Sinn" ${ }^{\text {90 }}$ oder "Der spricht bald wie ein Prediger.“91

Würde man nach der mystisch-allegorischen Bedeutung suchen, ist diese in einem christlichen Themenkomplex zu finden: So weist der Esel in der Bibel eine durchaus positive Konnotation auf, z.B. als der weissagende Esel Bileams (Mo 4, 22), der den Willen Gottes noch vor dem Menschen erkennt. Auch die Eselsmesse, die im Mittelalter am 14. Januar als eine Art Karneval-Veranstaltung gefeiert wurde und ursprünglich an die Flucht nach Ägypten (M 2, 13-15) erinnern sollte, ist positiv konnotiert. Aus dieser Tradition heraus entwickelte sich später das Narrenfest.92 Auch Bachtin beschreibt in Rabelais und seine Welt. Die Volkskultur als Gegenkultur den Esel als ein Tier, das die heilige Familie nach Ägypten führt. Ein Esel war auch oft Jesus' Begleiter. Doch schon immer gab zwei abweichende Auffassungen vom Esel: als Inbegriff von Demut und Sanftheit einerseits und als Symbolfigur für Faulheit, hemmungslose Geilheit und Dummheit andererseits, wobei die letztere im Mittelalter mit fehlender Glaubensbereitschaft gleichgestellt wurde.

In Kehlmanns Roman erfährt der Rezipient in einer Szene, wie sich der Junge Tyll im Mehl wälzt, dem Esel seines Vaters den Kopf abschneidet und den Eselskopf auf den eigenen aufstülpend auf einen Baum klettert. Einerseits aktualisiert diese Szene das bekannte Bild von Till Eulenspiegel mit Eselsohren; andererseits rekurriert diese Szene auf eine in eine Wand eingeritzte anonyme Darstellung aus dem 3. Jahrhundert mit der Inschrift: „Alexamenos betet seinen Gott an“, die den gekreuzigten Christus mit Esels-

89 Kehlmann, Tyll. Roman, 405.

90 Kehlmann, Tyll. Roman, 293.

91 Kehlmann, Tyll. Roman, 290.

92 Eine Beschreibung des Narrenfestes (Fête des Fous) liefert z. B. Victor Hugo in seinem Roman Der Glöckner von Notre-Dame. 
kopf zeigt.93 Auch der Baum, auf dem Tyll mit dem Eselskopf sitzt, lässt sich symbolisch als Kreuz verstehen. So würde Tyll mit dem Propheten Jesus gleichgesetzt. In dem christlichen Kontext wird auch Tylls literarischer Vater dargestellt, und zwar als Ketzer, dessen Vergehen jedoch nur darin besteht, nach dem Wissen zu trachten. Die Hinrichtung dieser Figur, die zu den wenigen des Romans gehört, die die Welt reflektieren, lässt sich gesellschaftskritisch interpretieren.

\section{4. „Postirony is ironic earnestness“94}

Seit dem späten Mittelalter, als Bote die Geschichten über den Schalk Till Eulenspiegel veröffentlichte, hat sich der Umgang mit Humor entscheidend verändert. So entsteht aus einem Esel, der ursprünglich nach Tills geschicktem Unterricht zwei Buchstaben erkennen kann, und zwar „I“ und „A“, ein sprechender Esel mit Konnotation zum Urvater der Textauslegung. Kehlmann verwandelt somit den auf Pointe zielenden, mittelalterlichen Humor in eine Postironie, bei der eine klare Differenzierung zwischen Ernst und Ironie kaum noch möglich ist. Der Autor setzt hier eine Ironie der Ironie ein, indem er die ursprüngliche Ironie bzw. ihre Pointe realisiert. Die Postironie transzendiert so die Ironie und macht sie und ihren strukturellen Aufbau sichtbar. Während die Ironie auf der inhaltlichen Ebene des Textes entwickelt wird, entfaltet sich die Wirkung der Postironie im Falle des sprechenden Esels außerhalb des Textes und hängt von der Fähigkeit des Rezipienten ab, das Spiel des Erzählers zu durchschauen..$^{95}$ Auch der Humor funktioniert in beiden Texten anders: Bei Till Eulenspiegel besteht der Witz darin, dass etwas, was es gibt (I-A-Laute des Esels) als ein Ergebnis von Tills Arbeit präsentiert wird, und da der Rezipient es besser weiß, kann er darüber lachen. Anders als in Botes Till Eulenspiegel, wo der Rezipient als mitwissender Komplize des Schalks Eulenspiegel über seine Scherze mitlachen kann, wird er bei Kehlmann zum Objekt des Sprachspiels. Es ist somit eine Verschiebung des Objekts des Lachens zu beobachten: Während bei Bote über diejenigen gelacht wird, die daran

93 Christus mit Eselskopf; gnostisches Geheimzeichen Y; Inschrift: „Alexamenos betet seinen Gott an". Wandritzung, zwischen 192 und 235 n. Chr. Aus der Pagenschule auf dem Palatin in Rom. Rom, Museo Palatino: BILDNUMMER: AKG84860.

94 Alex Shakar, The Savage Girl (New York: Harper, 2001), 140.

95 Unser Jahrhundert gilt als das Zeitalter der Postironie, die wiederum entweder in eine Hyperironie abdriften kann, die mit einem „zynischen Nihilismus“ gleich alle Wertmaßstäbe grundsätzlich infrage stellt, oder die Haltung der „Antiironie“ einnimmt. Vgl. Diana Porr, „Postironie“, in Lexikon zur zeitgenössischen Kunst von Com \& Com, hrsg. v. Markus Gossolt und Johannes H. Hedinger (Sulgen/Zürich: Niggli, 2010), 135. 
glauben, man könne den Esel tatsächlich lesen lehren, wird bei Kehlmann im Stillen über diejenigen gelacht, die sich vom Erzähler in die Irre leiten lassen und es vielleicht doch glauben, der Esel könne sprechen. ${ }^{96}$

Kann der Rezipient aber über die Postironie noch lachen? Lachen ist eine performative Reaktion auf einen gelungenen Humor. Auch wenn es der Wissenschaft bisher nicht gelang, eine alleingültige Definition des Humors zu liefern, lässt sich einiges zusammentragen, was darunter zu verstehen wäre. So betrachtet beispielsweise Sigmund Freud das eintretende Lachen als eine Ersatzreaktion, die an die Stelle der nicht erfüllten Erwartungen tritt, um die aufgebaute Spannung zu entladen. ${ }^{97}$ Aus rhetorischer Sicht tritt Lachen ein, wenn ein Devianzphänomen bzw. ein gerechtfertigter Fehler oder ein geplanter Bruch mit bestimmten Erwartungen auf eine humoreske Wirkung zielt und diese auch erreicht. Doch damit gelacht wird, muss der Humor entweder mit dem common sense brechen ${ }^{98}$ oder der Rezipient muss über ein Vorwissen verfügen, das es ermöglicht, den Bruch zu erkennen. Eine Grundlage hierfür ist sogar bereits in der antiken Rhetoriktheorie zu finden, wo zu lesen ist, dass die Verletzung des aptums, d. h. der Angemessenheit, humoreske Wirkungen erzielen kann. Eben darin besteht Till Eulenspiegels Komik. Doch bei Kehlmann ist Tyll kein Schelm mehr, sondern ein weiser Narr und Berater des Königshauses, wodurch er nur zum Repräsentanten der Komik, zu einem Symbol der Ironie reduziert wird. Dies ist allerdings nur möglich, weil Till Eulenspiegel als Klassiker der deutschen Literatur bereits mit Humor konnotiert ist. Das Lachen setzt normalerweise ein, wenn man die hinter der Ironie verborgene Wahrheit erkennt. Wird der Rezipient jedoch stets in Ungewissheit gelassen, so fehlt ein eindeutiger Moment der Erkenntnis und sodann das Lachen. Ob der Leser nun imstande ist, Postironie als solche zu erkennen, hängt nicht mehr von dem Text ab, sondern von seiner Bereitschaft das Gelesene als Ironie der Ironie zu erkennen. So verschiebt sich die Ironie von der Textebene auf die Ebene des Rezipienten. In Konsequenz sehen LeserInnen, die sich auf univokale Rezeption beziehen, die Simultaneität der verschiedenen Botschaften nicht. Sie erkennen daher womöglich auch keine Postironie, da sich diese auch als das Wahrnehmen des Wahrnehmens von Ironie umschreiben lässt.

Ironie und Ernst schließen einander aus. Die Postironie lässt sich dennoch als „ironischen Ernst“ bezeichnen, mit dem die Erwartungen der Leser

96 Was selbstverständlich nur eine der möglichen Interpretationen darstellt.

97 Sigmund Freud, „Der Witz und seine Beziehung zum Unbewußten“, in Sigmund Freud, Werkausgabe, Bd. 6, hrsg. v. Anna Freud u. a. (Frankfurt am Main: Fischer Taschenbuchverlag, 1999), 131-155.

98 Vgl. Alexander Baur und Nikola Wiegeler, Humor in der Rhetorik, http://www.rheton. sbg.ac.at/rheton/2011/11/humor-in-der-rhetorik/. 
restlos realisiert werden. Sie besteht nicht darin, gegen die Lesererwartungen zu schreiben, sondern diese eben gerade zu realisieren. Postironisch kann der Text sein, wenn unsere Erwartungen an den Text gegen uns arbeiten (David Foster Wallace). Die Postironie lässt sich zudem als Spiel mit der Grenze, als eine Möglichkeit des produktiven Umgangs mit Kontingenzen ${ }^{99}$ auffassen, wobei unter der Kontingenz der Versuch verstanden wird, eine Ganzheit herzustellen.

\section{Schlusswort}

In seinem Roman Tyll setzt Daniel Kehlmann, den Prämissen der Neuen Deutschen Lesbarkeit entsprechend, verschiedene Formen von Humor ein. Der Roman ist daher nicht nur als ein Versuch zu betrachten, die Grenzen des Humors auszuloten, sondern auch als einer, die Unterhaltungs- mit der gehobenen Literatur zu verbinden. Dabei war zu beobachten, dass sich eine im kulturellen Gedächtnis fest verankerte Wahrnehmung mancher Figuren, wie etwa die des humorvollen Schalks, durch eine dem Standard abweichende Darstellung kaum verändert. Auch der Krieg bleibt trotz der grotesken Darstellung in seiner Kategorie. So zeigt sich, dass es Figuren oder Phänomene gibt, die unerschütterlich mit der Kategorie Humor oder Ernst konnotiert sind, unabhängig von ihrer literarischen Verarbeitung. Des Weiteren ließ sich beobachten, dass Ironie und Postironie eine unterschiedliche Codierung verlangen. Denn während sich etwa die dramatische Ironie in jedem Text entwickeln lässt und einen aufmerksamen Rezipienten erfordert, zielt die Postironie auf Belesene, die diese auch außerhalb der inhaltlichen Textebene, zum Beispiel in einer bestimmten Verarbeitung des gegebenen Stoffes, erkennen. Zudem ist für die Postironie oft ein besonderer Rezeptionsmodus notwendig.

Daniel Kehlmann hat sich trotz der Thematik aus einer späteren historischen Epoche für eine Titelfigur aus dem Mittelalter entschieden: für einen Narren. Insbesondere Das Narrenschiff ${ }^{100}$ von Sebastian Brant machte die Figur des Narren zu einer Symbolfigur des 16. Jahrhunderts und trug sie bis in das 18. Jahrhundert hinein.101 Brant verfolgt mit seiner Darstellung der Narrheiten und menschlicher Laster im Sinne von docere ein didaktisches Ziel, indem er den Weg zur Vernunft in der durch das (Aus-)Lachen hervor-

99 Vgl. Sebastian Plönges, „Postironie als Entfaltung“, in Medien und Bildung. Institutionelle Kontexte und kultureller Wandel, hrsg. v. Torsten Meyer u. a. (Wiesbaden: VS Verlag für Sozialwissenschaften, 2011), 438-446.

${ }^{100}$ Alternativ: Daß Narrenschyff ad Narragoniam, 1494.

101 Vgl. Volker Maid, Metzler Literatur Chronik. Werke deutschsprachiger Autoren (Stuttgart/Weimar: Verlag J.B. Metzler, 3., erw. Aufl., 2006), 98. 
gebrachten Selbsterkenntnis sucht. ${ }^{102}$ Weitere Beispiele für diese Art der Ironie sind Lob der Torheit (1509) von Erasmus von Rotterdam oder das Volksbuch über die Schildbürger und ihre selbstverschuldete Narrheit, an deren Beispiel übrigens die unerwünschten Folgen der Verstellung verbildlicht werden. Denn, um die fortschreitende Entvölkerung der Stadt zu verhindern, die aufgrund des Dienstes vieler Bürger als Ratgeber verschiedener Regierenden drohte, fangen die Bürger an, ihre Dummheit vorzutäuschen, bis sie jedoch tatsächlich ihre ursprüngliche Klugheit endgültig verlieren. Doch während der Humor seit dem späten Mittelalter (z. B. die Schwänke von Hans Sachs) eine kritische Auseinandersetzung mit der Welt auslösen sollte, dient er in der Gegenwartsliteratur im Sinne der Neuen Deutschen Lesbarkeit vorwiegend der Unterhaltung. ${ }^{103}$

\section{References}

Balzter, Stefan. Wo ist der Witz? Techniken zur Komikerzeugung in Literatur und Musik. Berlin: Erich Schmidt Verlag, 2013.

Baur, Alexander, and Nikola Wiegeler. Humor in der Rhetorik. 2011. http://www.rheton.sbg.ac.at/rheton/2011/11/humor-in-der-rhetorik.

Behler, Ernst. "Ironie." In Historisches Wörterbuch der Rhetorik, edited by Gert Ueding, co-founded by Walter Jens. In collaboration with Wilfried Barner, Dietrich Briesemeister et al., vol. 4: Hu-K, 599-624. Tübingen: Max Niemeyer Verlag, 1998.

Behler, Ernst. Ironie und literarische Moderne. München/Paderborn/Wien/ Zürich: Ferdinand Schöning Verlag, 1997.

Bender, Niklas. Die lachende Kunst. Der Beitrag des Komischen zur klassischen Moderne. Freiburg i.Br./Berlin/Wien: Rombach Verlag, 2017.

Benjamin, Walter. "Der Erzähler. Betrachtungen zum Werk Nikolai Lesskows." In Gesammelte Schriften II, 2, edited by Rolf Tiedemann, and Hermann Schweppenhäuser, 438-465. Frankfurt am Main: Suhrkamp, 1977.

102 Die Überwindung der Narrheit führt durch eine Selbsterkenntnis: „Dann wer sich für ein narren acht Der ist bald zu eym wissen gmacht.“ Vgl. Sebastian Brant, Das Narrenschiff, Nach der Erstausgabe (Basel 1949) mit den Zusätzen der Ausgaben von 1495 und 1499 sowie den Holzschnitten der deutschen Originalausgaben, hrsg. v. Manfred Lemmer (Tübingen: Max Niemeyer Verlag, 1986), 4.

${ }^{103}$ Baur und Wiegeler unterscheiden sechs Humorwirkungen: 1. Humor unterhält, 2. Humor löst negative Affekte auf, 3. Humor lenkt ab, 4. Humor bezweckt Gruppenkohäsion, 5. Humor tadelt und kritisiert, 6. Humor bildet das Image und inszeniert das eigene Ethos (den Charakter). Vgl. Alexander Baur und Nikola Wiegeler, Humor in der Rhetorik, 2011, http://www.rheton.sbg.ac.at/rheton/2011/11/humor-in-der-rhetorik/. Dieser Auflistung wäre nun eine weitere Kategorie hinzuzufügen: „Humor sells“. 
Borgers, Jorge Luis. "Kafka und seine Vorläufer." In Borgers, J.L. Inquisitionen, 118-121. Frankfurt am Main: Suhrkamp, 1992.

Bote, Hermann. "Ein kurzweiliges Buch von Till Eulenspiegel aus dem Lande Braunschweig. Wie er sein Leben vollbracht hat. Sechsundneunzig seiner Geschichten," edited by Siegfried H. Sichtermann. Berlin: Insel Verlag, 2017.

Brant, Sebastian. Das Narrenschiff. Nach der Erstausgabe (Basel 1949) mit den Zusätzen der Ausgaben von 1495 und 1499 sowie den Holzschnitten der deutschen Originalausgaben, edited by Manfred Lemmer. Tübingen: Max Niemeyer Verlag, 1986.

Das Komische, edited by Wolfgang Preisendanz, and Rainer Warning. München: W. Fink Verlag, 1976.

Diekmannshenke, Hajo, Neuhaus Stefan, and Schaffers Uta. "Vorwort." In Das Komische in der Kultur. Unter Mitarbeit von Eva Stubenrauch, edited by Hajo Diekmannshenke, Stefan Neuhaus, and Uta Schaffers, 11-21. Marburg: Tectum Verlag, 2015.

Freud, Sigmund. "Der Witz und seine Beziehung zum Unbewußten." In Freud, Sigmund. Werkausgabe, vol. 6, edited by Anna Freud, and Edward Bibring, and Willy Hoffer, 131-155. Frankfurt am Main: Fischer Taschenbuchverlag, 1999.

Fuß, Peter. Das Groteske. Ein Medium des kulturellen Wandels. Köln/Weimar/Wien: Böhlau Verlag, 2001.

Horn, András. Das Komische im Spiegel der Literatur. Versuch einer systematischen Einführung. Würzburg: Könighausen \& Neumann, 1988.

Iser, Wolfgang. "Das Komische: ein Kipp-Phänomen." In Das Komische, edited by Wolfgang Preisendanz, and Rainer Warning, 398-402. München: W. Fink Verlag, 1976.

Kayser, Wolfgang. Das sprachliche Kunstwerk. Bern: Francke, 1969 (i. 0. 1948).

Kehlmann, Daniel. Tyll. Roman. Reinbeck bei Hamburg: Rowohlt, 2017.

Kriegserfahrungen erzählen, edited by J.Rogge. Bielefeld: transkript Verlag, 2016.

Lapp, Edgar. Linguistik der Ironie. Tübingen: Gunter Narr Verlag, 2nd edition, 1991.

Lorenz, Maren. “Tiefe Wunden, Gewalterfahrung in den Kriegen der Frühen Neuzeit." In Gesellschaft - Gewalt - Vertrauen. Jan Philipp Reemtsma zum 60. Geburtstag, edited by Ulrich Bielefeld, Heinz Bude, and Bernd Greiner, 332-353. Hamburg: HIS Verlagsges. mbH, 2012.

Maid. Volker. Metzler Literatur Chronik. Werke deutschsprachiger Autoren. Stuttgar/Weimar: Verlag J.B. Metzler, 3rd expanded edition, 2006.

Müller, Marika. Die Ironie. Kulturgeschichte und Textgestalt. Würzburg: Königshausen \& Neumann, 1995. 
Plönges, Sebastian. "Postironie als Entfaltung." In Medien und Bildung. Institutionelle Kontexte und kultureller Wandel, edited by Torsten Meyer, Wey-Han Tan, Christina Schwalbe, and Ralf Appelt, 438-446. Verlag für Sozialwissenschaften, Wiesbaden, 2011.

Politycki, Matthias. "Kalbfleisch mit Reis! Die literarische Ästhetik der 78erGeneration." In Matthias, Politycki. Die Farbe der Vokale. Von der Literatur, den 78ern und dem Gequake satter Frösche, 23-44. München: Luchterhand, 1998.

Porr, Diana. "Postironie." In Lexikon zur zeitgenössischen Kunst von Com\&Com, edited by Markus Gossolt, and Johannes H. Hedinger, 135. Sulgen/Zürich: Niggli, 2010.

Rickes, Joachim. "Der Esel ist nicht der Esel. Zu Daniel Kehlmanns Ungewissheitspoetik in 'Tyll'". Sprachkunst, no. 49 (2018): 73-86.

Rogge, Jörg. "Kriegserfahrungen erzählen - Einleitung." In Kriegserfahrungen erzählen, edited by Jörg Rogge, 9-30. Bielefeld: transkript Verlag, 2016.

Schaper, Benjamin. Poetik und Politik der Lesbarkeit in der deutschen Literatur. Heidelberg: Universitätsverlag Winter, 2017.

Schmidt-Dengler, Wendelin, and Klaus Zeyringer. "Komische Diskurse und literarische Strategien. Komik in der österreichischen Literatur - eine Einleitung." In Komik in der österreichischen Literatur, edited by Wendelin Schmidt-Dengler, Johann Sonnleitner, and Klaus Zeyringer, 9-19. Berlin: Erich Schmidt Verlag, 1996.

Scholten, Clemens. "Origenes (AT)." In Das wissenschaftliche Bibellexikon im Internet (WiBiLex). 2007. https://www.bibelwissenschaft.de/wibilex/das-bibellexikon/lexikon/sachwort/anzeigen/details/origenesat/ch/0b1d6575c18a7f90f4aea21ace221413/.

Seeber, Stefan. Poetik des Lachens. Untersuchungen zum mittelhochdeutschen Roman um 1200. Berlin/New York: Walter de Gruyter, 2010.

Shakar, Alex. The Savage Girl. New York: Harper, 2001.

Stierle, Karlheinz. "Komik der Handlung, Komik der Sprachhandlung, Komik der Komödie." In Das Komische, edited by Wolfgang Preisendanz, and Rainer Warning, 237-268. München: W. Fink Verlag, 1976.

\section{Zwischen Komik und Postironie. Die Spielarten des Humors in Tyll von Daniel Kehlmann}

\footnotetext{
Abstract: In seinem Roman Tyll lotet Daniel Kehlmann die Grenzen des Humors aus, und zwar indem er u. a. das Komische mit dem Ernsten vermischt oder die Postironie einsetzt. Der vorliegende Beitrag untersucht die Spielarten des Humors und Verfahren zur Erzeugung von Komik, die Kehlmann in seinem Roman sowohl auf der Sprachebene als auch in der Konstruk-
} 
tion und im Inhalt des Romans unterschiedlich verarbeitet. Zudem liefert Tyll einige Beispiele für Postironie, d. h. eine Ironie der Ironie, also ein literarisches Verfahren, das die Ironie zu transzendieren vermag, indem $u$. a. ihre Pointe realisiert wird.

Schlüsselwörter: Daniel Kehlmann, Tyll, Humor, das Komische, Postironie, deutschsprachige Gegenwartsliteratur.

\title{
Między komizmem a postironią. Wariacje humoru w powieści Tyll Daniela Kehlmanna
}

\begin{abstract}
Abstrakt: Daniel Kehlmann w powieści Tyll bada granice humoru, m.in. mieszając komizm z powagą czy stosując postironię. W artykule analizie poddane zostają odmiany humoru i metody tworzenia komizmu, zastosowane przez Kehlmanna zarówno na poziomie języka, w samej strukturze powieści oraz na poziomie treści. Autor powieści posługuje się również postironią, czyli ironią ironii, jako zabiegiem literackim polegającym na przekraczeniu ironii, m.in. poprzez realizację puenty.
\end{abstract}

Słowa kluczowe: Daniel Kehlmann, Tyll, humor, komizm, postironia, niemieckojęzyczna literatura współczesna. 